\title{
Quantitation of Albumin in Serum Using "Turn-on" Fluorescent Probe with Aggregation-Enhanced Emission Characteristics
}

Wangyang Li, ${ }^{\ddagger}$ Didi Chen, ${ }^{\ddagger}$ Huan Wang, Shanshan Luo, Lichao Dong, Yahui Zhang, Jianbing Shi, ${ }^{*}$ Bin Tong, Yuping Dong ${ }^{*}$

School of Materials Science and Engineering, Beijing Institute of Technology, Beijing, 100081, China

E-mail: bing@bit.edu.cn; chdongyp@,bit.edu.cn 

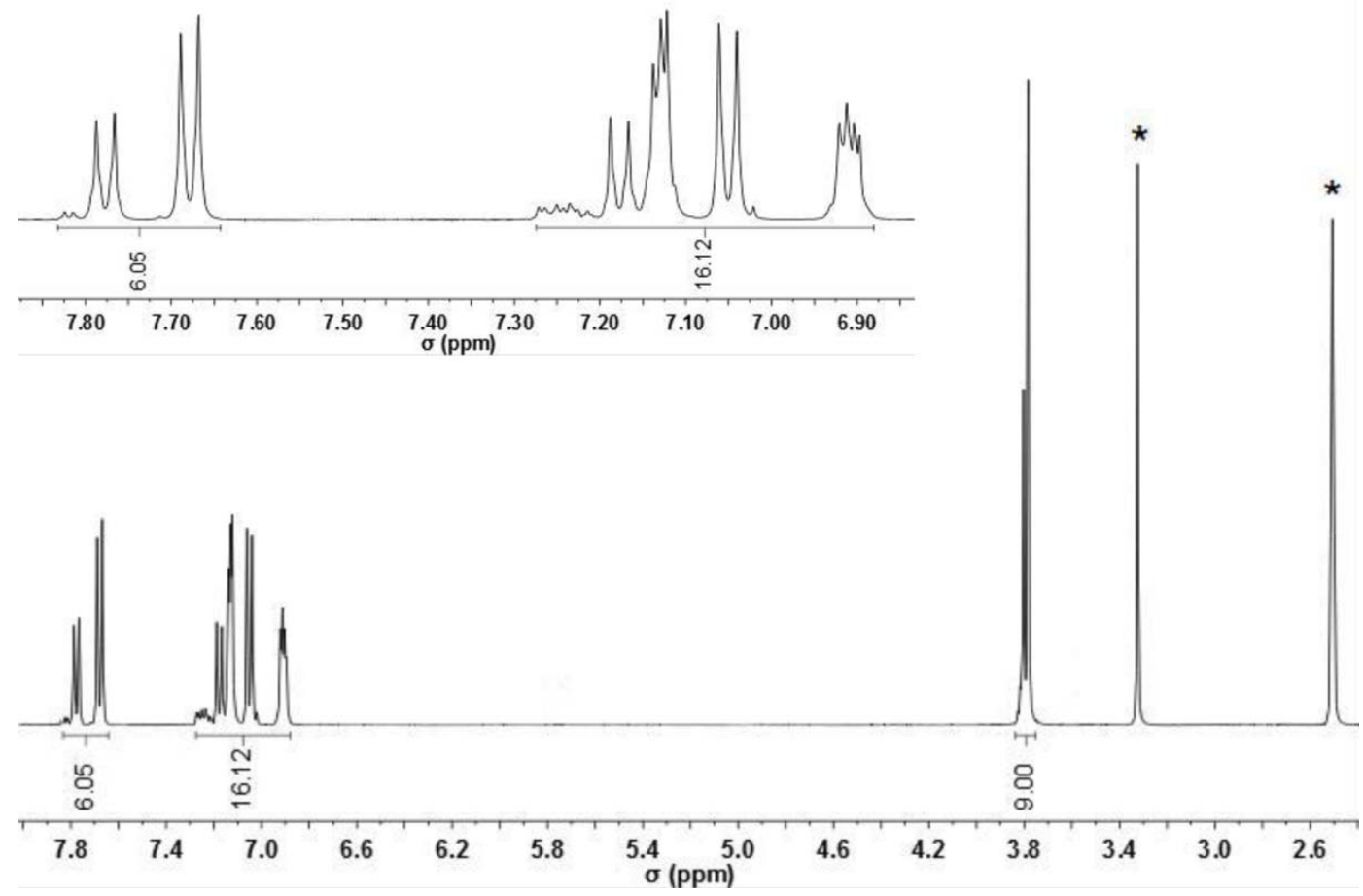

Figure S1. ${ }^{1}$ H-NMR spectra of DP-TPP. Solvent: DMSO

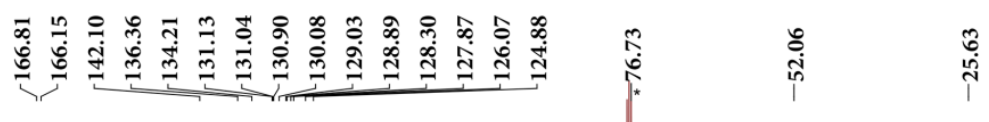

${ }^{13} \mathrm{C}$ NMR $\left(101 \mathrm{MHz}, \mathrm{CDCl}_{3}\right) \delta 166.81,166.15,142.10,136.36,134.21$, $131.13,131.04,130.90,130.08,129.03,128.89,128.30,127.87,126.07$, $124.88,76.73,52.06,25.63$.

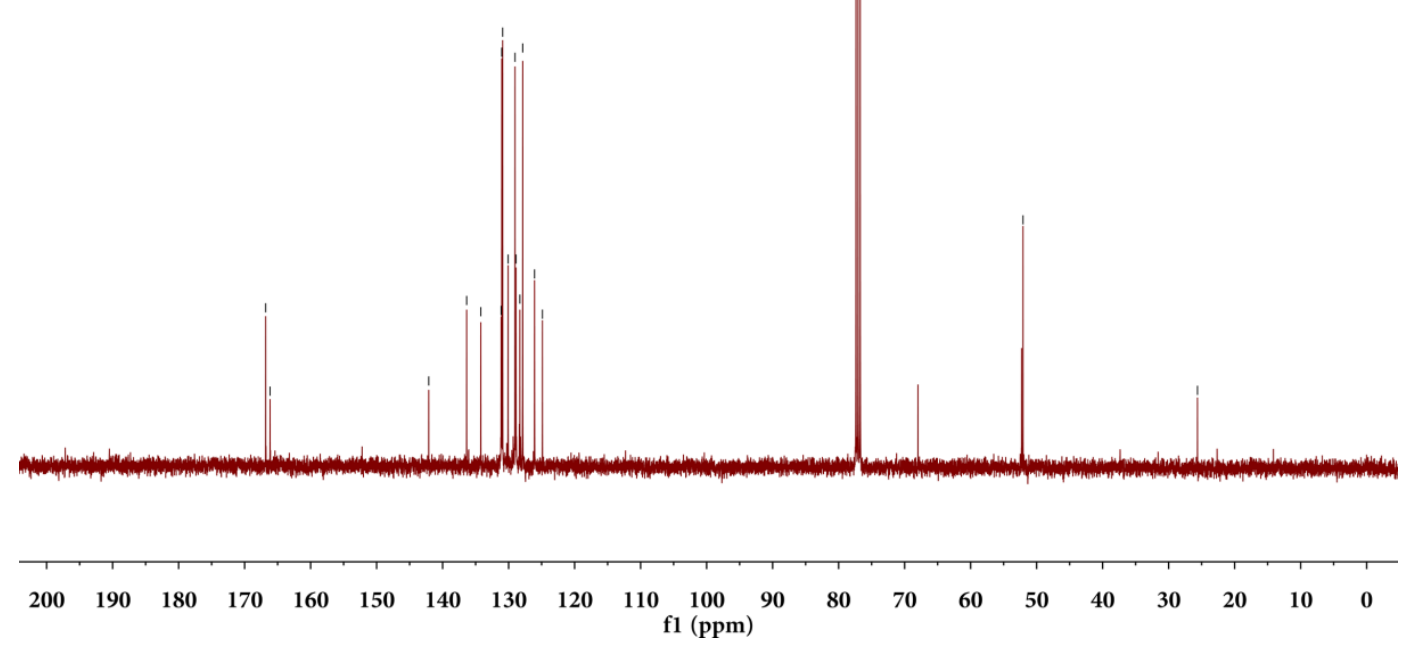

Figure S2. ${ }^{13} \mathrm{C}-\mathrm{NMR}$ spectra of DP-TPP. Solvent: $\mathrm{CDCl}_{3}$ 


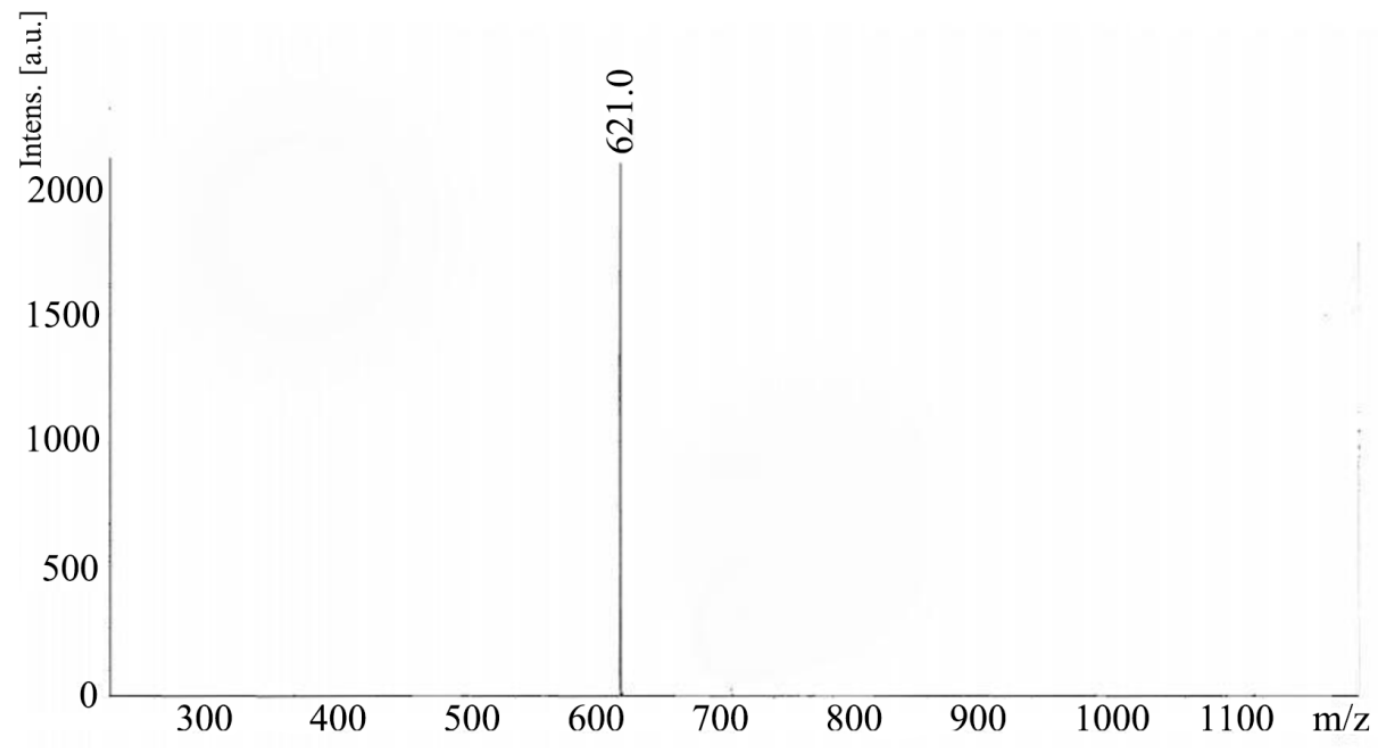

Figure S3. MALDI-TOF spectra of DP-TPP

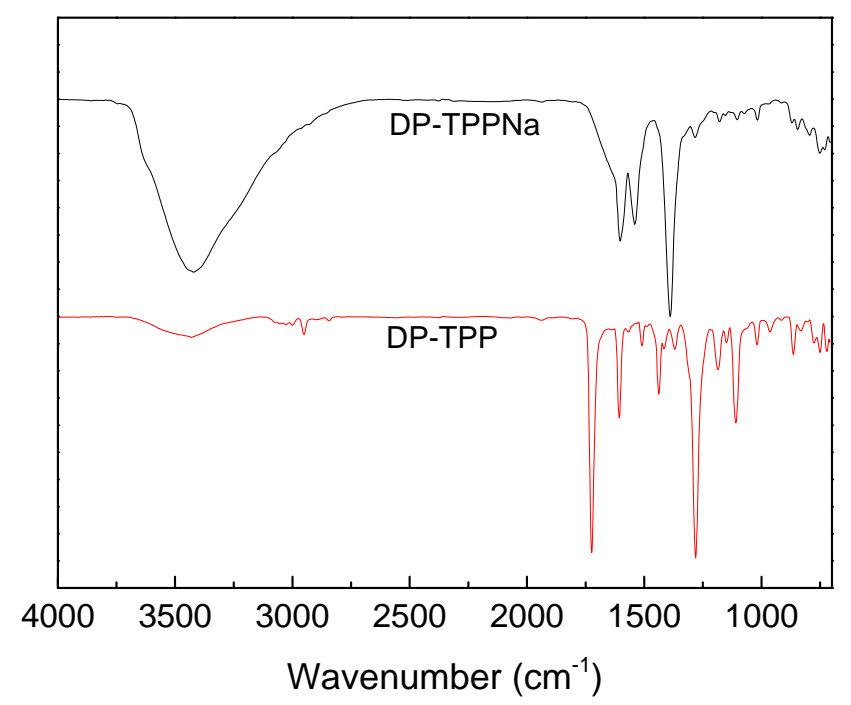

Figure S4. FT-IR spectra of DP-TPP and DP-TPPNa 


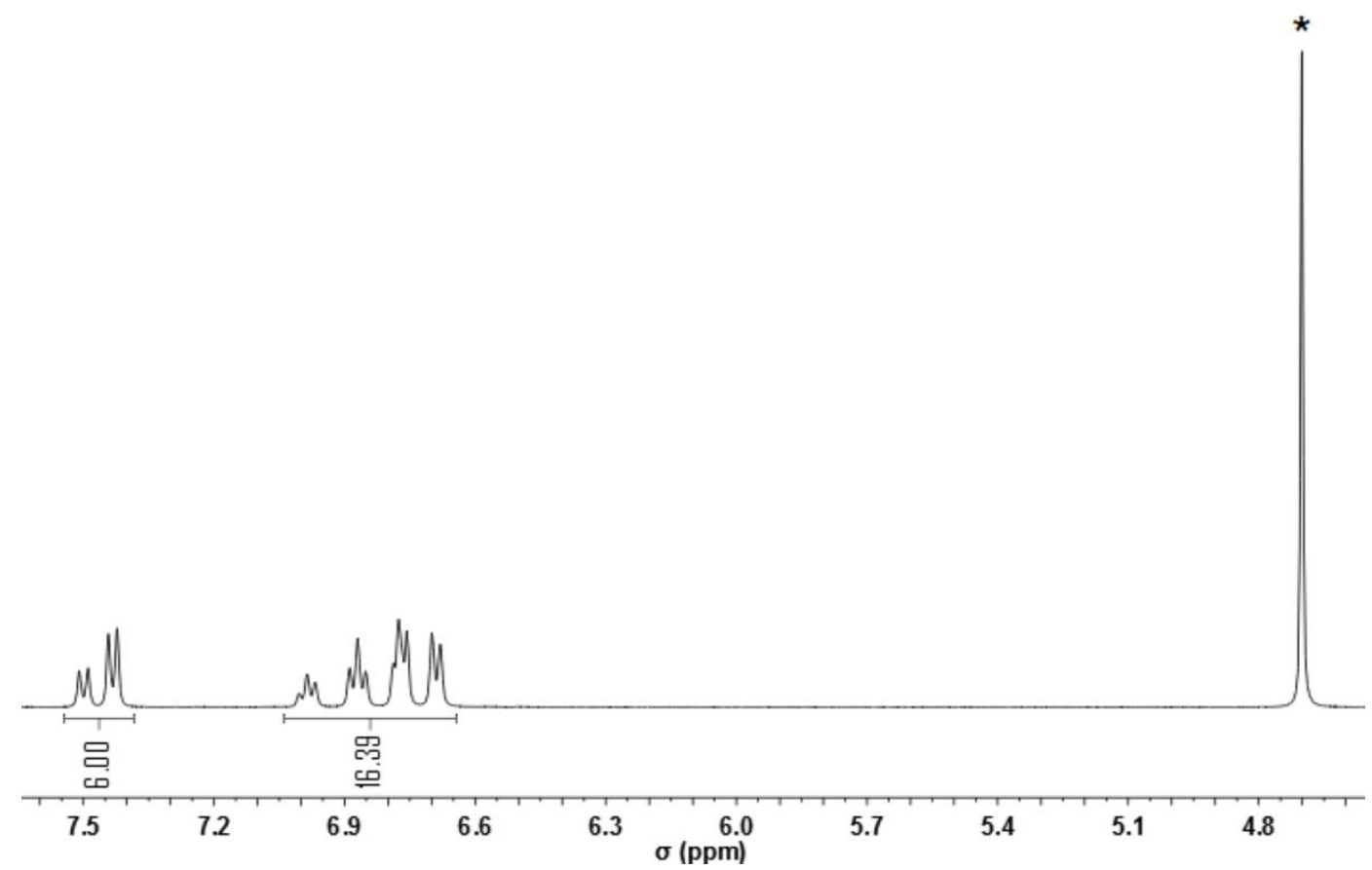

Figure S5. ${ }^{1} \mathrm{H}-\mathrm{NMR}$ spectra of DP-TPPNa, solvent: $\mathrm{D}_{2} \mathrm{O}$

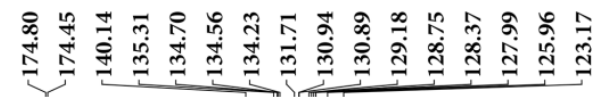

${ }^{13} \mathrm{C}$ NMR $\left(101 \mathrm{MHz}, \mathrm{D}_{2} \mathrm{O}\right) \delta 174.80$,

$174.45,140.14,135.31,134.70,134.56$

$134.23,131.71,130.94,130.89,129.18$,

$128.75,128.37,127.99,125.96,123.17$

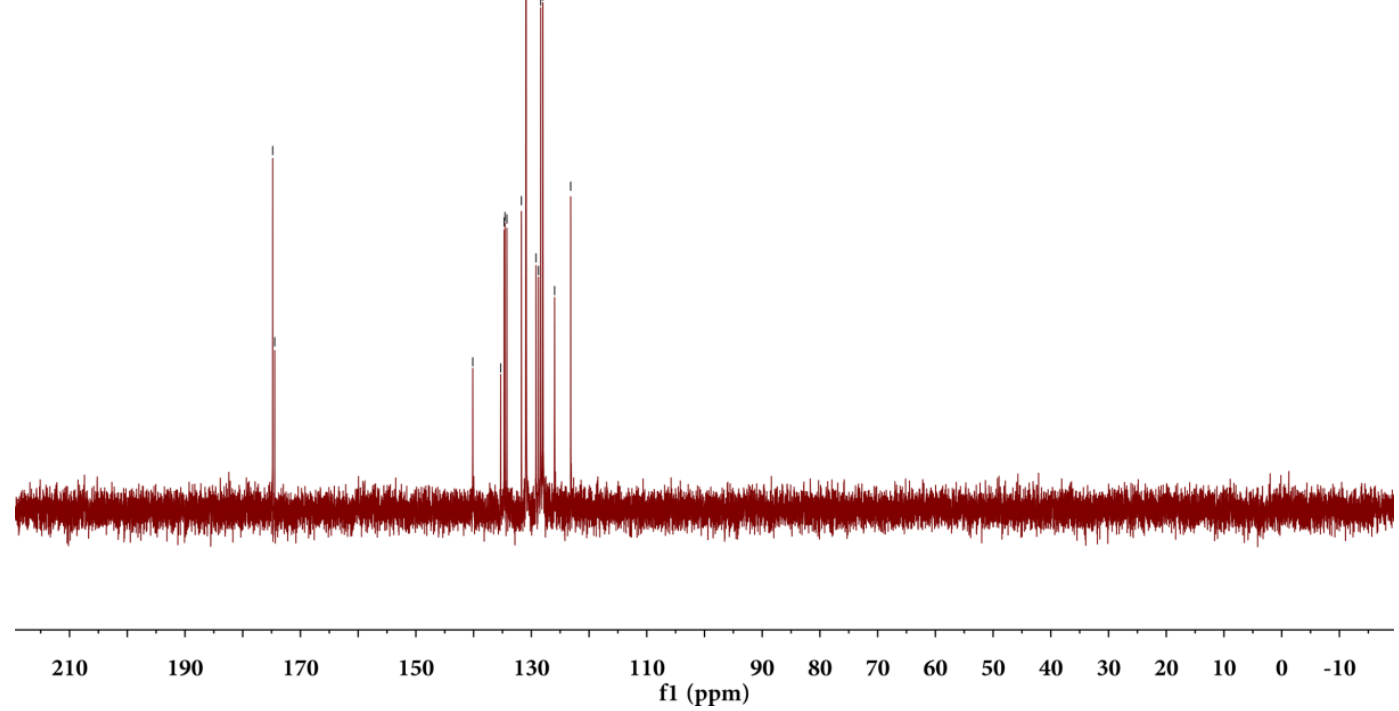

Figure S6. ${ }^{13} \mathrm{C}-\mathrm{NMR}$ spectra of DP-TPPNa, solvent: $\mathrm{D}_{2} \mathrm{O}$ 


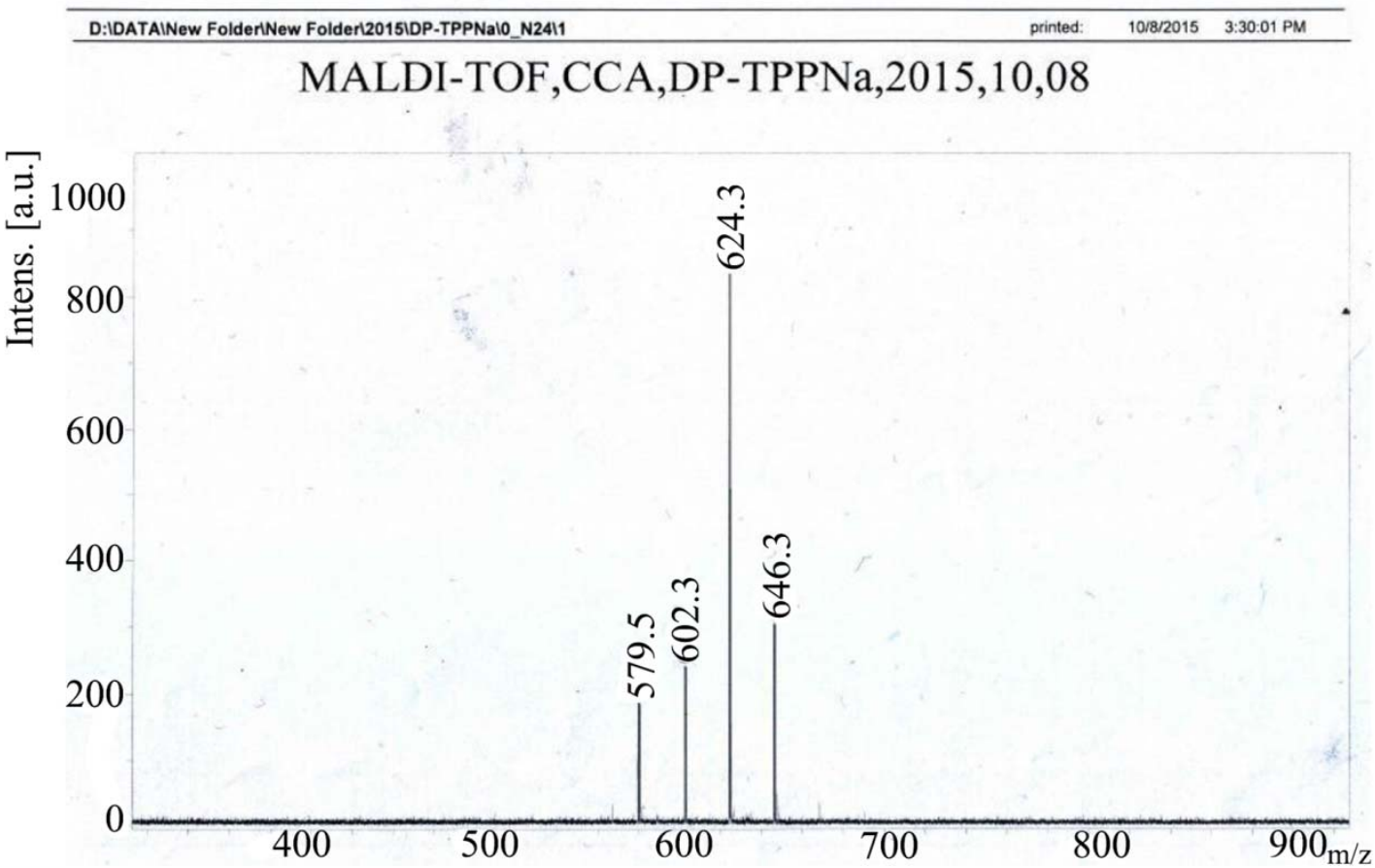

Figure S7. MALDI-TOF spectra of DP-TPPNa

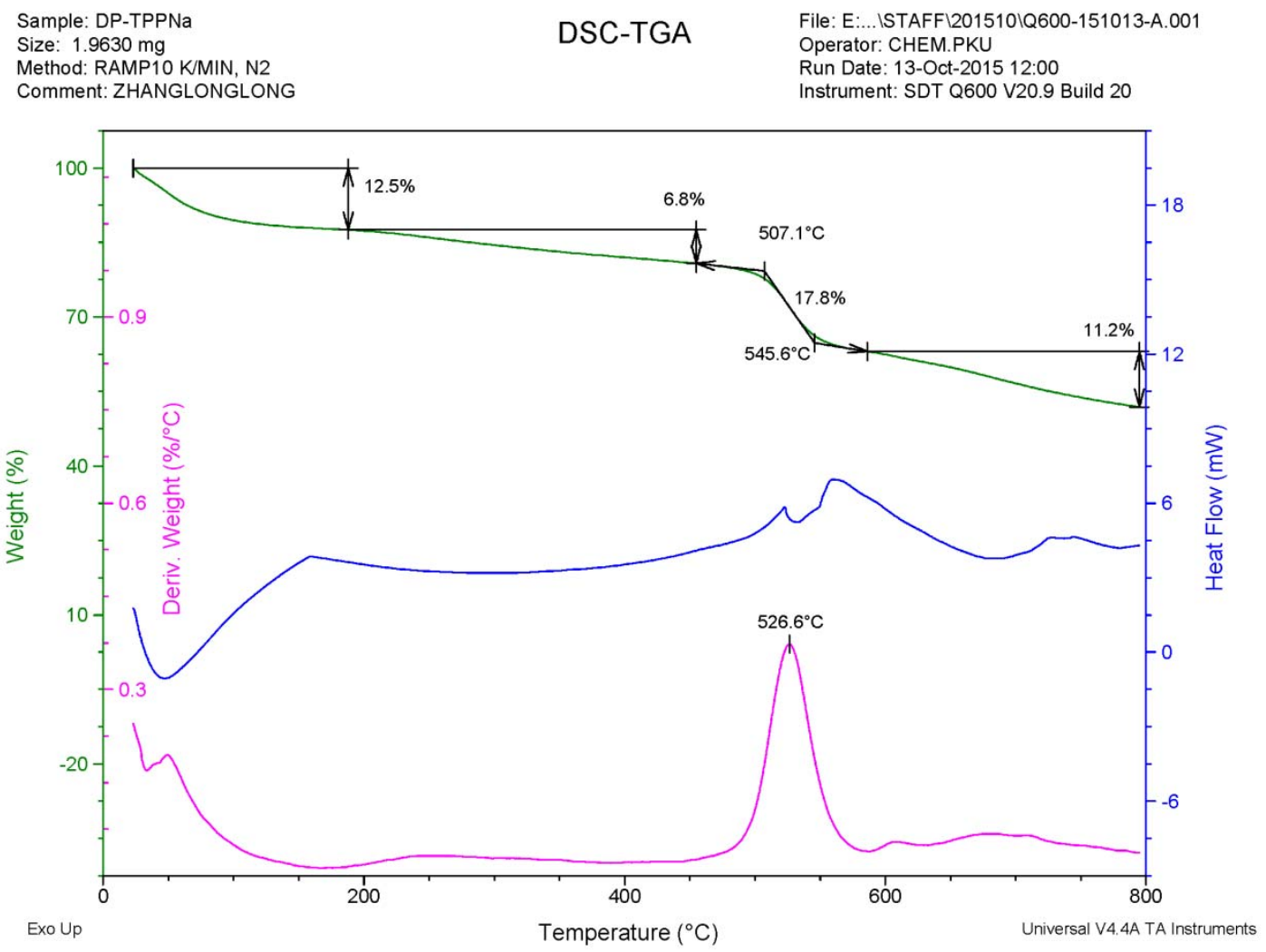

Figure S8. TGA-DSC spectra of DP-TPPNa 


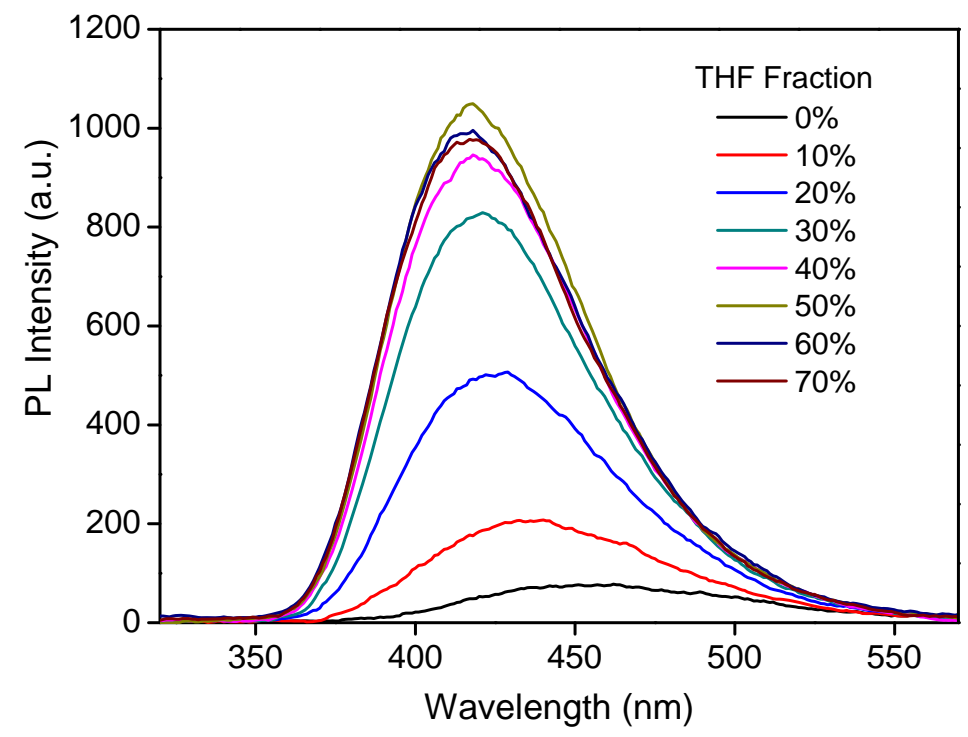

Figure S9. PL spectra of DP-TPPNa in PBS-THF mixture.

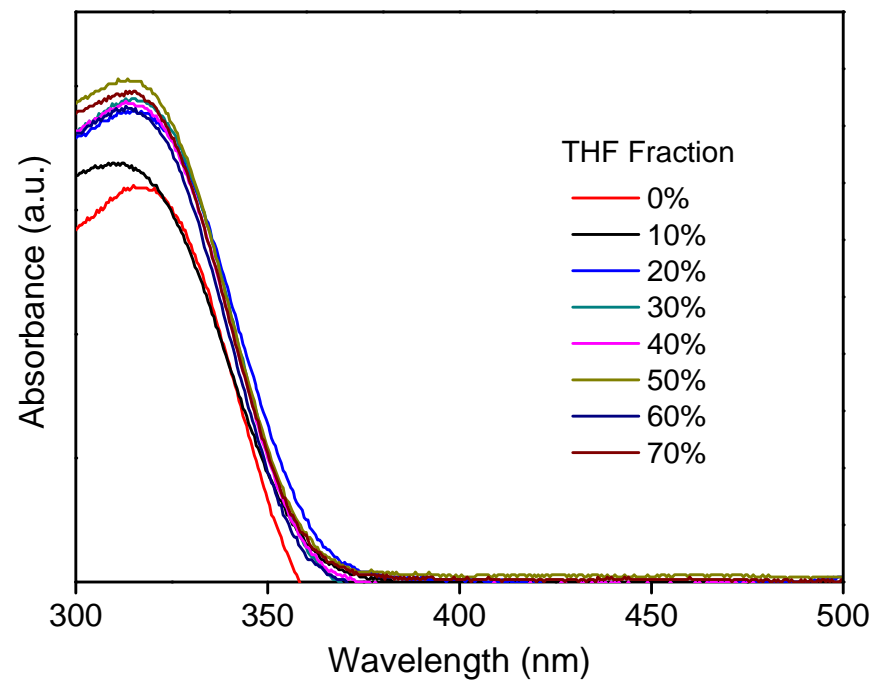

Figure S10. UV-Vis spectra of DP-TPPNa in PBS-THF mixture. 


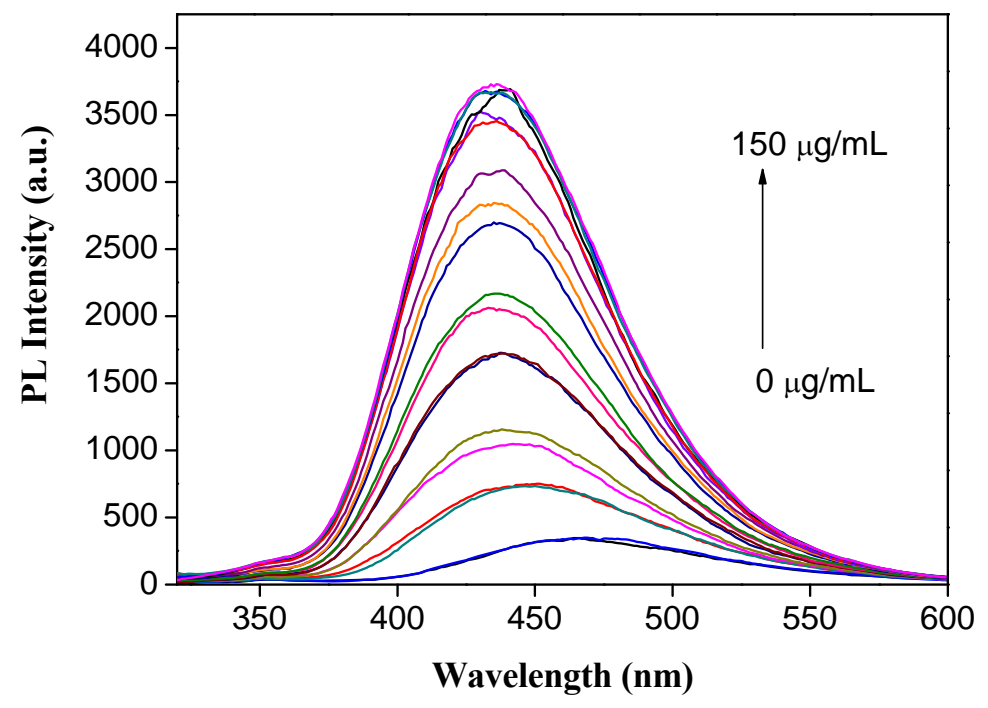

Figure S11. PL spectra of DP-TPPNa in PBS buffer containing different concentrations of HSA $(0-150 \mu \mathrm{g} / \mathrm{mL})$. [DP-TPPNa] $=10 \mu \mathrm{M} ; \lambda_{\text {ex }}=310 \mathrm{~nm}$.

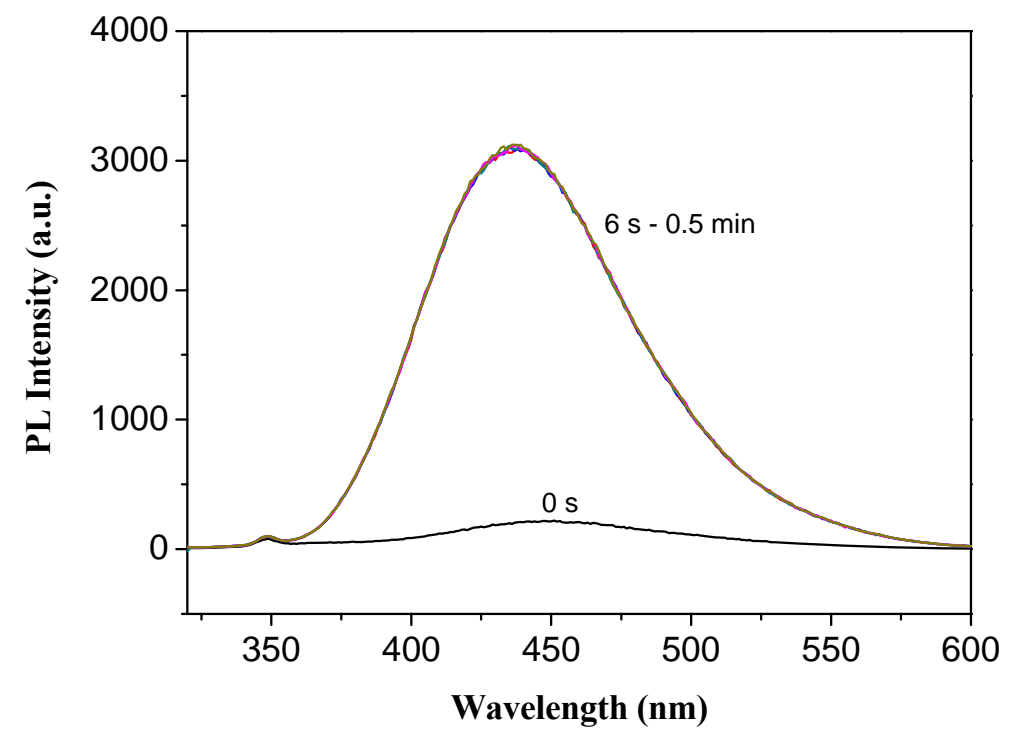

Figure S12. PL spectra of DP-TPPNa in PBS buffer containing BSA at different time. $[\mathrm{DP}-\mathrm{TPPNa}]=10 \mu \mathrm{M} ;[\mathrm{BSA}]=50 \mu \mathrm{g} / \mathrm{mL} ; \lambda_{\mathrm{ex}}=310 \mathrm{~nm}$. 


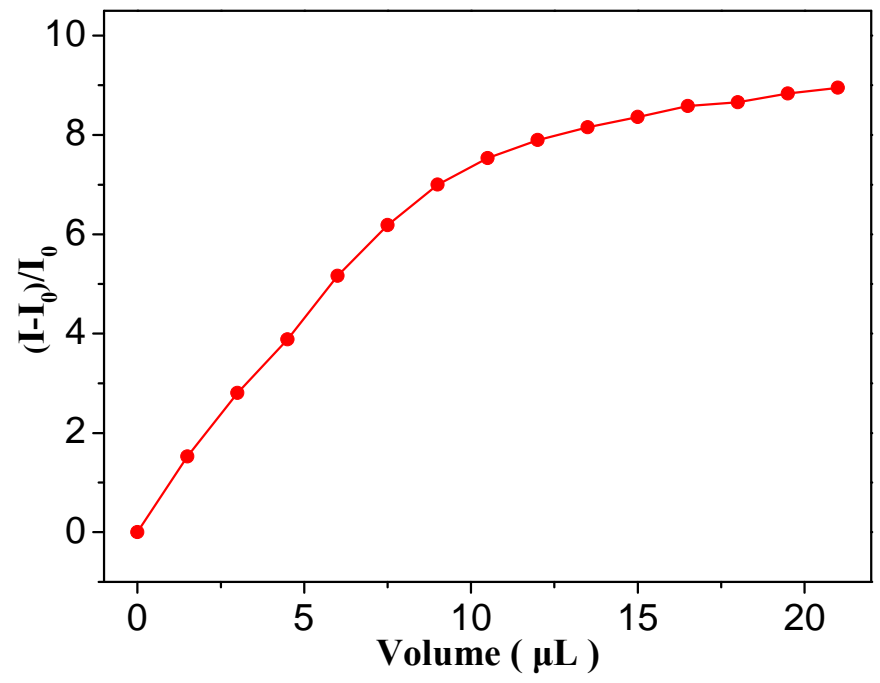

Figure S13. Plots of relative PL intensity at $\sim 433 \mathrm{~nm}$ with FBS volume in PBS buffer $(0-21.0 \mu \mathrm{L})$. [DP-TPPNa] $=10 \mu \mathrm{M} ; \lambda_{\mathrm{ex}}=310 \mathrm{~nm}$.
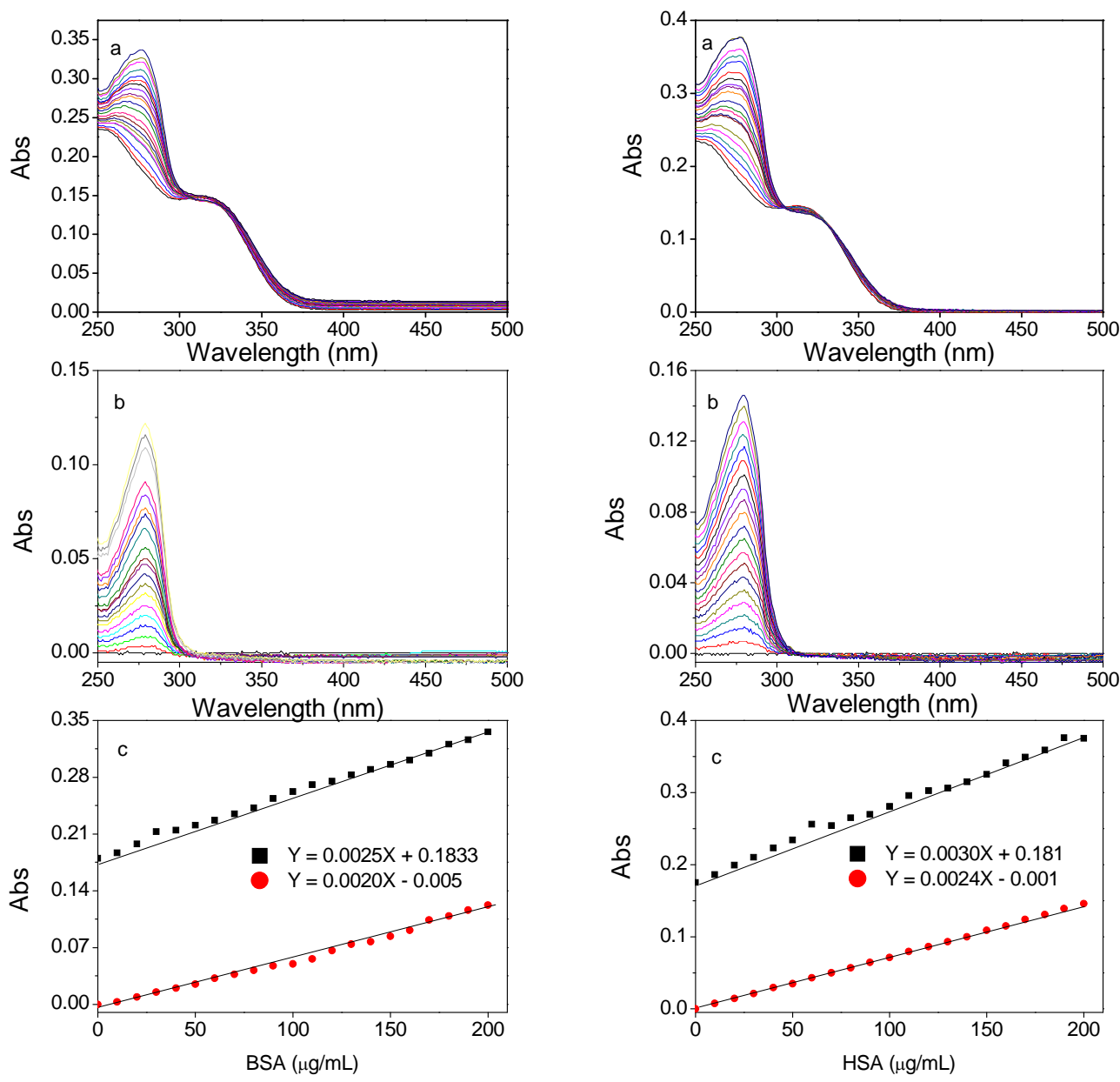
Figure S14. UV-Vis spectrum of BSA and HSA in the presence (a) and absence (b) of DP-TPPNa. The relationship between the absorbances at $279 \mathrm{~nm}$ and the volume of BSA and HSA (c). [DP-TPPNa] $=10 \mu \mathrm{M} ; \lambda_{\mathrm{ex}}=310 \mathrm{~nm}$.

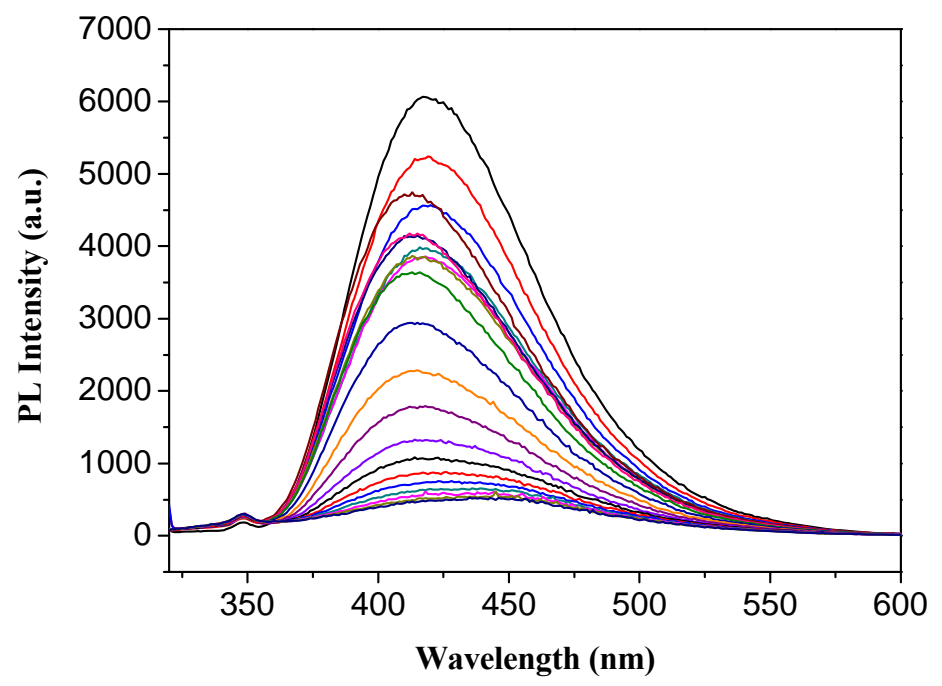

Figure S15. PL spectra of DP-TPPNa in water with different concentration of $\mathrm{GndHCl}$ in the presence of BSA. [DP-TPPNa] $=10 \mu \mathrm{M} ;[\mathrm{BSA}]=100 \mu \mathrm{g} / \mathrm{mL} ; \lambda_{\text {ex }}=310$ nm. 